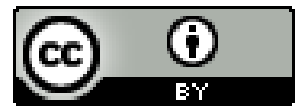

\title{
O PROCESSO DE(S)COLONIZADOR NA PERFORMANCE ARTE "MUMBUCA": DO FAZER ARTÍSTICO-CRIATIVO AOS ATRAVESSAMENTOS POÉTICOS E AFETIVOS
}

\author{
Ana Carolina Costa dos Anjos ${ }^{1}$
}

\author{
Thiago Francysco Rodrigues Cassiano ${ }^{2}$
}

Resumo: O artigo resulta de pesquisas realizadas sobre a comunidade de Mumbuca, quilombo sediado no Estado do Tocantins - Brasil, culminando em uma produção artístico performativa. Para isso, foi escolhido um percurso em que se apresenta, primeiramente, um breve histórico da comunidade e, em seguida, aborda-se a produção artística desenvolvida sobre o quilombo tocantinense, relacionando toda produção artístico-criativa ao processo de de(s)colonização da população da diáspora africana por meio da obra performativa intitulada Mumbuca, pela perspectiva da valorização de cultura e identitário dessa comunidade. Para isso, utilizou-se pesquisas bibliográficas, narrativa oral e exploratória.

Palavras-chave: Quilombo Mumbuca, Performance Arte, Descolonização, Diáspora Africana, Identitário

\section{THE (DE)COLONIZER PROCESS IN THE PERFORMANCE "ARTE MUMBUCA": FROM THE CREATIVE-ARTISTIC PRACTICE TO POETIC AND AFFECTIVE CROSSING}

\begin{abstract}
This article is a result of researches realized about the people from "Mumbuca", a quilombo located in the state of Tocantins - Brazil. The work culminated in a performative artistic production. Firstly, a brief history of the community is presented, followed by a discussion of the artistic production about the quilombo. Than, all the creative-artistic production is related to the (de)colonization process of the population derived from the African diáspora through the performative piece named "Mumbuca". This relation is made by a perspective of the appreciation of this people's culture and identity. To do so, this work used bibliographic and exploratory researches, as well as oral narratives.
\end{abstract}

Keywords: Quilombo Mumbuca, Art Performance, Decolonization, African Diaspora, Identity.

\section{EL PROCESO DE-COLONIZADOR EN LA PERFORMANCE "ARTE MUMBUCA":} HACER EL REVELADOR A LOS ATRAVESAMIENTOS POÉTICOS Y AFECTIVOS

\footnotetext{
1 Graduada em Comunicação Social/Jornalismo (2012), Especialista em Ensino de Comunicação/Jornalismo: Temas contemporâneos (2017), Mestre em Ciências do Ambiente (2015) todos pela Universidade Federal do Tocantins (UFT), atualmente é Doutoranda em Sociologia na Universidade Federal de São Carlos.

${ }^{2}$ Formado em Licenciatura em Artes Visuais pela UNIP - Universidade Paulista (2016). Formado em Teatro Licenciatura pela UFT - Universidade Federal do Tocantins (2019). Especialista em Docência do Ensino Superior pela FAVENI - Faculdade Venda Nova do Imigrante (2019).
} 
Resumen: Los resultados de las actividades de investigación en la comunidad de Mumbuca, el tema no se encuentra en el estado de Tocantins - Brasil, culminando en una producción de producción. Para ello, también para el programa de aprendizaje, la primera, la historia de la comunidad y el futuro, es un producto de la técnica de desarrollo de música, que coincide con la producción, la técnica y el proceso del proceso de producción. La población de África afronta los díaspora para mi trabajo final Mumbuca, la perspectiva de la apreciación de la cultura y la identidad de la comunidad. Para el esto, utiliza bibliografía bibliográfica, las narrativas y las exploraciones bibliográficas.

Palabras clave: Quilombo Mumbuca, Rendimiento Arte, Descolonización, Diáspora Africana, Identidad.

\section{INTRODUÇÃO}

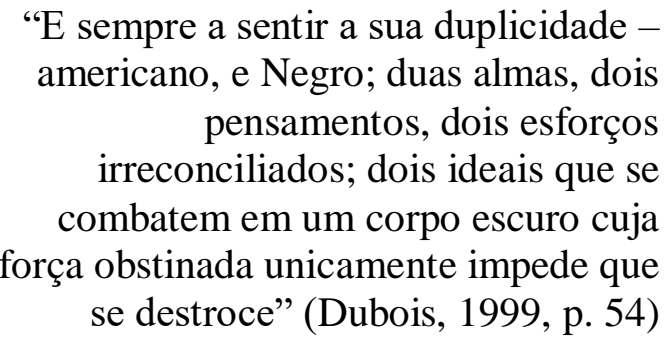

Como confluência de outras pesquisas e textos, experivivências e experimentações artísticas que esse artigo surge, sua escrita é atravessada por um outro texto, um diário de bordo denominado Diário dos Sentidos e Permissões, no qual um dos autores (Thiago) relata os atravessamentos estéticos, poéticos, afetivos e culturais obtidos durante a pesquisa. Sendo assim, quando ao longo do texto relatar sobre o Diário dos Sentidos e Permissões, é sobre este instrumento de pesquisa que se refere. Além desse texto, outro elemento que compõe essa escrita são estudos sobre o quilombo Mumbuca localizado no interior do Estado do Tocantins, Brasil. Um adendo sobre esse texto é que um resumo expandido do mesmo fora apresentado no $\mathrm{X}$ Congresso Brasileiro de Pesquisadores Negros (Copene), com título: “A criação artística como um processo liberta-dor: afrodiasporicos, quilombo e os atravessamentos poéticos afetivos".

Para este artigo o percurso textual que apresentamos se dá: traçando primeiramente um breve histórico sobre a comunidade (quilombo Mumbuca), para, em seguida, abordar o insight para a produção artística inspirada na comunidade em questão. Assim, o processo artístico performativo surge a partir do reconhecimento da falta de igualdade para com o identitário afrodiaspórico e suas especificidades e manifestações, sendo consequência do processo colonizador sofrido pela comunidade de Mumbuca do Tocantins e por toda população da diáspora africana no Brasil, seja ela de forma institucionalizada ou não. 
Sendo assim, é por meio das artes visuais e do fazer artístico-criativo que se encontram formas de resistência e existência e esse texto faz um relato teórico de uma produção artístico performativa. Produção essa que se fez mesmo com o processo colonizador que pesa sobre as costas da população de Mumbuca, epor ser estrutural pesa em toda população afrodiaspórica ${ }^{3}$. Acredita-se que a força de uma identidade vindoura da África, seja ela de forma ressignificada no corpo, nas manifestações populares; ou quanto todos esses processos do culturus do "negro", são oprimidas em diversos níveis, todavia há um corpo-pele e, com ele, uma identidade que não se pode silenciar, sendo esse nosso ponto de partida e de retornos, se há estruturas opressores há agentes da diáspora africana resistindo, vivendo e expondo formas criativas de transpor dores e criar horizontes de expectativas. Desse modo, trata-se de expor um corpo que também é discursivo, afinal, como diz Beatriz Nascimento, sendo citada por Ratts (2007), é um corpo que traz em si uma travessia implicada de geopoéticas.

O processo de desenvolvimento da pesquisa contou com a criação do já referido Diário dos Sentidos e Permissões ${ }^{4}$, cujo intuito não fora apenas o registro fenomenológico etnográfico como de costume. Para além disso, seu principal objetivo é servir como um espaço destinado ao registro de atravessamentos afetivos, estéticos, culturais e questionadores durante os estudos. O citado diário vem então como um legado de pesquisa, bem como de relações e correlações entre autores ao longo dessa trajetória, fazendo-se um instrumento potente e disparador para nossa escrita de agora. Transver a experiência de Mumbuca dilatando o olhar para outros elementos e motrizes culturais desse comunidade foi o que proporcionou a transposição de uma realidade para outro espaço, neste caso, o das artes. Um adendo importante é que durante o texto abordaremos, por vezes, o termo "terra-chão", compreendido não apenas na significação de espaço físico, como algo além, pois ao colocar-se desta forma, quer se abordar a terra-origem e mítica, repleta de uma singularidade, de um ethos, seus saberes e fazeres.

Os atravessamentos estéticos e poéticos-afetivos experienciados pelos estudos e

\footnotetext{
${ }^{3}$ Ao longo desse texto falamos de estruturas institucionais do governo estadual (Tocantins) e municipal (Mateiros-To) que subjugam a comunidade de Mumbuca, mas em um outro texto também de nossa autoria discutimos estruturas semelhantes no município de Palmas (To, Capital da fé), no qual inferimos haver racismo religioso. "Cultura e Religiosidade Afro-Brasileira: a exclusão do identitário negro no evento "palmas - capital da fé", publicado na Revista da Associação Brasileira de Pesquisadores/as Negros/as (ABPN), [S.1.], v. 10, n. Ed. Especi, p. 295-312, jun. 2018.

${ }^{4} \mathrm{~A}$ escolha do nome se deu por crer que um atravessamento afetivo, estético ou cultural ocorre somente quando existe a permissão do indivíduo que entra contado como novas experiências. Sem a alteridade, ou seja, permissão ao novo, o que ocorre é relato não experienciado afetivamente. Vale destacar, que o referido documento é produção apenas de um dos autores, no caso, Thiago Francysco Rodrigues Cassiano.
} 
sensações obtidas por meio da comunidade quilombola traçam um caminho ao subjetivo, cognitivo e afetivo. Portanto, é um transver de uma identidade pela perspectiva da natureza sensível, pautado pelas relações humanas e da natureza em sua plenitude. Conforme aponta Pino (1997), essas perspectivas são os fenômenos afetivos que representam a forma com que os acontecimentos reverberam, repercutem na natureza sensível do indivíduo e, assim, o conjunto de realidades, contextualizadas criase o sentido afetivo. Esse sentido afetivo é a mola propulsora da criação artística e elemento constitutivo da urdidura acadêmica. Perpassando pela ótica humanista - de um novo humanismo, aquele instado por Frantz Fanon (2008), artística e política, construímos este artigo com conteúdos factuais e experienciais a partir da realidade, no qual o resultado é exposto em uma experimentação artística. Mesmo que subjetivo, o transpor da realidade política e social de Mumbuca à arte performativa faz com que artista e espectador experienciem- por outro ângulo - um ethos de forma a criar indagações e percepções acerca do trabalho experimentado. Dessa forma, criam-se inquietudes políticas, afetivas e sociais, pois cremos que, se a arte não for para criar inquietude, então já se faz morta, e, por esse ângulo, entende-se arte e política fundidas em um campo semiótico e subjetivo, no qual as experiências subjetivas no seu fazer e apreciar, afeta indivíduos. Esse mesmo indivíduo faz parte da realidade, estando sujeito às interrupções e esbarramentos ${ }^{5}$ afetivos, estéticos e sociais dessa própria realidade e das sociedades, mundo e formas de mundo que o cerca, tece sua realidade (Berger; Luckmann, 2004). Assim, entende-se que cada ser humano, mesmo que seja por escolha não pode torna-se uma 'ilha humana' inerte da influência direta ou indireta de outras culturas e manifestações identitárias, visto que as relações se estabelecem pela identificação afetiva, como afirma Pino (1997). Sendo assim, uma vez desenredadas as lentes vamos de encontro ao povoado de Mumbuca.

\section{QUILOMBO MUMBUCA DO ESTADO DO TOCANTINS: SILENCIAMENTOS INSTITUCIONAIS}

Segundo Dolce; Medeiros (2014), a comunidade quilombola Mumbuca está situada no município de Mateiros, a cerca de $360 \mathrm{~km}$ de Palmas, capital do Tocantins, e foi fundada por dois casais, esses casais são de pessoas descendentes de africanos que

\footnotetext{
${ }^{5}$ Termo utilizado pela perspectiva das relações humanas, no que se diz respeito aos encontros com outras culturas e identidades
} 
foram escravizados no Brasil $^{6}$. Hoje, a comunidade possui 46 famílias, totalizando aproximadamente 100 pessoas. Até o ano de 2001, não possuíam energia elétrica e, em 2017-2018, Mumbuca ainda sofre com a falta de saneamento básico e com a precariedade de estradas que dificultam o acesso a outros locais e a serviços públicos. A saber, à época desta escrita deste texto, a comunidade não possuía acesso à medicina convencional de forma que a opção única era recorrer às ervas do cerrado. Sobre isso, vale apontar que:

(...) Mesmo com o avanço da medicina em diversas partes do mundo, no Brasil, as plantas medicinais costumam ser uma das alternativas para parte da população, principalmente a de baixa renda, devido a diversos fatores, dentre os quais, o custo alto dos medicamentos industrializados e o acesso restrito a um sistema de saúde de qualidade. Em contrapartida, o uso deste tipo de terapia tem crescido também entre as pessoas de maior poder aquisitivo, na busca por opções terapêuticas mais saudáveis. (CAVAGLIER; MESSEDER,2014, p. 56)

Perante o exposto, vale destacar que, enquanto uns recorrem aos saberes ancestrais para cura das doenças e mazelas, outros possuem a medicina não formal como alternativa, uma alternativa, via de regra, capitalizada, já que é notável o engendramento de um sistema capital financeiro e de importâncias imperando em nossa sociedade. Não que a medicina não convencional deva ser desvalorizada, pelo contrário, o que chamamos a atenção é sobre a falta de acesso de uns fronte à possibilidade de escolha de outros em uma mesma sociedade.

Retomando a Mumbuca, Doce; Medeiros (2014) apontam que a economia da comunidade gira em torno do artesanato em capim dourado e buriti, e dos produtos com eles produzidos. Hoje, o capim dourado é símbolo do Estado do Tocantins ${ }^{7}$. Com o Buriti são feitas violas que tocam a história da comunidade, em contraste com as músicas evangélicas ouvidas da única igreja do Mumbuca. Atualmente, boa parte da comunidade se declara evangélica, desconhecendo - e até criticando - religiões de matriz africana, provavelmente seguidas por seus antepassados. Sobre isso, um pensamento empírico: o esquecimento e o abandono de nossas origens, neste âmbito, vêm como um dos legados deixados pela colonização, faz com que o colonizado seja uma árvore cuja a raiz fora retirada de sua terra-chão-estrutura. Perdem-se as referências

\footnotetext{
${ }^{6}$ Optou-se por utilizar o termo descendentes de pessoas escravizadas e não "descendente de escravo" como no texto original, pois acredita-se que nenhuma pessoa surge escrava, mas se torna escravo devido aos processos colonizadores durante a história do mundo.

${ }^{7}$ Em Anjos (2017), vê-se como foram as estratégias políticas de como o capim dourado se tornou um símbolo do estado, igualmente, como houve a apropriação e/ou esvaziamento simbólico do mesmo para os artesãos que trabalhavam com ele, ocorrendo a quebra da tecnologia patrimonial.
} 
e identidades, nas quais o abuso social é por vezes forma impositiva e classificatória chancelada aos que chamamos sem- raiz, ou seja, aos seres humanos sem ligações físicas e afetivas como sua origem. Como estar, se não se sabe quem és? ${ }^{8}$ Além da exploração cultural da mão de obra barata, a comunidade sofre com o avanço do agronegócio. Existe ainda o silenciamento institucional de forma declarada para com o quilombo Mumbuca. Em agosto de 2016, a única ponte de acesso à comunidade foi queimada de forma criminosa (COSTA, 2016). Por força de uma ação civil pública, a Prefeitura Municipal de Mateiros (TO) foi acionada para construção de uma nova ponte (G1 Tocantins, 2016), essa informação corrobora com o descaso sofrido pelas pessoas de Mumbuca.

Ilhados, sem o direito civil de ir e vir, garantido no art. 5, XV, CF (Brasil, 1988), os moradores de Mumbuca realizaram um financiamento coletivo para a construção de uma nova ponte. O valor solicitado foi de $\mathrm{R} \$ 80.000,00$, mas conseguiram apenas $\mathrm{R} \$ 1.500,00^{9}$. Perante o fato, inferimos que, conforme aponta Moura (2000, p. 25)

\begin{abstract}
Todos os movimentos que desejam mudança social são movimentos políticos apesar do fato dos seus agentes coletivos não terem total consciência disto. $\mathrm{O}$ que vale e determina é o nível de consciência social de cada um e as propostas subsequentes (sic) para a mudança projetada. Mas todos se enquadram (com maior ou menor nível de consciência social) na proposta da transformação revolucionária (ou não) da sociedade (MOURA, 2000, p. 25).
\end{abstract}

O silenciamento sofrido pelos moradores de Mumbuca é uma continuação do que os africanos sofreram ao atravessar o Atlântico, quando tudo lhes fora tirado. Retirada de bases simbólicas da cultura de sujeitos e coletivos é o mesmo que retirar uma árvore de seu aterramento biológico onde se sustenta, deixando-a subordinada aos ventos das incertezas, no aguardo de presságios de uma emancipação motriz que a retire do asfalto do colonizador. O pertencimento social, nesse aspecto, surge como uma faca de dois gumes, excluindo uma tradição em prol de um aterramento cultural já préestabelecido, ou seja, o canônico. Os vindos da terra-África, ao serem (trans)plantados em solo brasileiro, necessitaram formar outras raízes firmes, lutando contra o desmatamento imoral do colonizador de forma a findar os adubos da consciência afetiva afrodiasporádica e da resistência de uma terra esquecida em seus descendentes, ${ }^{10}$. Vale destacar que, uma das ações da colonização é esta de jogar o que não considera

\footnotetext{
${ }^{8}$ Extraído do Diário dos Sentidos e Permissões.

${ }^{9}$ Site de arrecadação colaborativa Kickante.

${ }^{10}$ Autor 1, "Diário dos Sentidos e Permissões”, s/p.
} 
interessante nas sarjetas do esquecimento social, a não ser quando essa visibilidade possui fins mercadológicos, como, por exemplo, um antigo bar de alto padrão da cidade de Palmas-Tocantins, que chamava-se "Mumbuca" (ou ainda no processo de construção de nação $)^{11}$. O mais intrigante é perceber que, com o fechamento do estabelecimento, no ano de 2017, no mesmo local, e com uma estrutura mais luxuosa e elitizada, o bar é reaberto, no mesmo ano. O estabelecimento, agora sob nova direção e propriedade dos cantores sertanejos, Gusttavo Lima e Marrone, passa a se chamar "Coronel's"12. No período histórico onde casa grande e senzala eram legais pelo âmbito constitutivo, os coronéis do café oprimiam as pessoas vindas da África, o que faz com que se torne de uma comicidade de mal gosto ter que analisar que, em pleno século XXI, esse processo social de interesse culturais para fins financeiros segue em metáforas.

Embora tenhamos apresentado Mumbuca e apropriações de Mumbuca apostamos teórica e a artisticamente no "terceiro espaço", esse espaço há possibilidades de criar novas estruturas e traduções, posto que o que existe não dá conta da experivivência afrodiaspórica, nem no passado nem no tempo presente. É preciso uma nova gramática, novos julgamentos cognitivos para urdir uma nova narrativa, deslocando os conhecimentos fixados que criaram os "sistemas de significação e organização social" (Bhabha apud Rutherford, 1996, p. 36). Por isso, e por querer falar de novas produções seguimos para o relato da performance artística.

\section{PERFORMANCE ARTE MUMBUCA: O PROCESSO ARTÍSTICO-CRIATIVO E OS ATRAVESSAMENTOS AFETIVOS, ESTÉTICOS E SÓCIO-POLÍTICOS}

As pessoas cuja ancestralidade está em África e é racializada são estigmatizadas em seu fazer artístico em detrimento às influências europeias nas artes e seu lugar nas artes silenciado. A nós, pessoas da diáspora africana, é dada a

\footnotetext{
${ }^{11}$ Uma narrativa sobre o esvaziamento dos símbolos identitários da população vindoura da África para formação da nação, de um povo e de uma cultura brasileira pode ser lido em Anjos; Sousa (2017) "Estratégias de Conservar o Poder: a construção midiática do termo apropriação cultural e o caso do uso turbante". Revista da Associação Brasileira de Pesquisadores/as Negros/as (ABPN), [S.1.], v. 9, n. 23, p. 249-266, nov. 2017.

12“'Inaugurado em 2017, conta com uma parceria entre o Marrone e o Gusttavo Lima. Juntos, nossos Coronéis querem levar o conceito de Grill e Bar Sertanejo para o todo o Brasil. Criado para satisfazer todos os gostos e idades. O Coronel's Grill e Bar oferece uma gastronomia brasileira internacional feita para agradar todos os paladares. Nossas opções de entretenimento vão de música ao vivo a brinquedoteca toda equipada e com supervisão de monitoras preparadas para garantir que cada momento que você passe no Coronel's seja o mais bem aproveitado possível". Retirado do site do referido estabelecimento: coronelgrillebar.com.br
} 
descrença e a insignificância para com nossos saberes e fazeres. Assim, para nós, arte é sinônimo de classificações de jogos de importâncias, onde sempre nos é dado o mínimo, quando é dado o direito à expressão, seja por meio institucional, privado ou pela esfera civil. Somos definidos como baderneiros, arruaceiros e sexualizados pela perspectiva cristã, onde pensar e produzir artisticamente se torna impossível.

Essa política de estereótipos faz parte de um discurso colonial bastante disseminado, o qual, por meio de livros, mapas, desenhos, pinturas, censos, jornais e propagandas vai criando um mundo engessado enquanto representação, feito cartografia com lugar previamente delimitado e definido. (SCHWARCZ; VAREJÃO, 2014, p.13).

Ou seja, em todos os espaços, o processo de exclusão do identitário de pessoas afrodiaspóricas é reforçado, ocorrendo em diversos âmbitos e esferas sociais. Retomando às artes, torna-se pontual e raro ver pessoas da diáspora africana urbana contando suas próprias histórias de forma orgulhosa, ou as histórias de seus ancestrais ${ }^{13}$, independentemente na narrativa artística escolhida. A forte dominação opressora europeia nos faz assumir a crença de que o belo é apenas o europeu e que nós, homens e mulheres da diáspora africana, não podemos pensar artisticamente a partir de nossas experiências, em outras palavras há um lugar para pessoas da diáspora africana na cultura, mas esse lugar é subalternizado. Desse modo, a arte se torna para nós apenas objeto de apreciação estética do fazer europeu (devido aos silenciamentos) ou o que produzimos não é considerado arte, assim, pensando em um regime de representações torna-se difícil utilizar da arte e suas narrativas como manifestação do pensar, agir e de uma existência social, política e estética.

As manifestações culturais e artísticas da população da diáspora africana precisam também ocupar todos os espaços artísticos, sem distinção étnica. A escravatura causou mazelas, além da crença do não pertencimento. Portanto, produzir artisticamente sobre as pessoas da comunidade Mumbuca, de certa forma também é falar de identidades de grupos de pessoas que, a fórceps, atravessou o Atlântico e luta diariamente para manter sua cultura viva, manter sua raiz firme em um solo que historicamente não lhes pertencia (pela ótica espaço, agora, transmutou-se em um território, nos processos de desterritorialização e reterritorialização, mas essa não é,

\footnotetext{
${ }^{13}$ Para Dubois é preciso ensinar as crianças sobre a história de seus ascendentes a fim de mitigar ao longo das gerações os impactos do racismo e da discriminação. Um projeto produzido entre 1909-1963, "The Encyclopedia of the African and African American Experience", finalizado por Henry Louis Gates e Kwame Anthony Appiah, em 2009.
} 
por ora, nossa pauta).

A colonização sofrida pelos vindouros da África pode atuar em diversas facetas, explícitas e não explícitas, nas quais se criam justificativas em mais ramificados aspectos para fazer sentido à opressão. Um dos autores (Thiago Cassiano) dedicou durante o processo de criação artística deste objeto de arte performativa a experimentar andar pela cidade Palmas (TO) e São Paulo (SP) em diferentes locais: supermercados, cinemas, cafés, shoppings populares, escolas públicas e universidades; e perceber qual é a forma que uma pessoa da diáspora africana, de pele preta, se porta frente ao branco, como o seu corpo reage a esse contato, quais suas reações e percepções visuais e físicas. Uma experiência que considero assustadora: 'negros' ainda olham para não 'negros' de olhos baixos, em um ar claramente de inferioridade, a senzala ainda olha para casa grande. Assentos em transportes públicos vazios ao lado de um homem 'negro', trajando moletom e capuz, mesmo com transporte público lotado de pessoas em pé. Olhares desconfiados ao ver um 'negro' entrando em uma agência bancária trajando vestimentas simplórias, situações já conhecidas pela sociedade, mesmo que negada por uns, ela existe e é diária. Ou ainda, o estranhamento ao ver jovens afrodiasporádicos como pesquisadores.

Porém, saber e experienciar são campos completamente diferentes; é preciso ser 'negro' para sentir na pele essas mazelas, nesse ponto estamos falando sobre dores vividas, como também é preciso ser da comunidade de Mumbuca para sentir o que é ter seu direito de ir e vir negado de forma declarada pelos governos estadual e municipal, nesse caso estamos falando sobre dores percebidas. Esse experimento pautou-se por meio da ampliação do olhar e dos sentidos em prol de analisar não apenas o processo de colonização como forma estrutural das negritudes brasileira, levando-me para um transver da realidade racista em que vivemos. No que diz respeito à percepção dos corpos negros frente ao colonizador, trouxe-nos a percepção do tônus corpóreo de submissão e inferiorização para o corpo negro performativo como instrumento desta criação.

Os quilombos brasileiros ${ }^{14}$, assim como Mumbuca, são considerados expressão físicas da resistência da população da diáspora africana no Brasil em existir após o

\footnotetext{
${ }^{14}$ Aqui entendidos como comunidades rurais de resistência, territórios nos quais se reúnem a população vindoura da África, bem como indígenas que resistiram e resistem aos diversos processos socioeconômicos, iniciados com a escravidão e continuados no século XXI com agrobusiness. Embora hajam outras entradas para o Quilombo como categoria, como a proposta da autora Ana Carolina, em pesquisar Cyberkilombagem (quilombos na internet).
} 
processo colonizador a ele inferido. Mesmo com todo o estigma que cai sobre os quilombolas, os quilombos são herança de uma cultura vinda da África, reelaborada, transformada, modificada, experienciada e traduzida na diáspora (terceiro-espaço). Ainda no século XXI, essa população continua a ser vista como inferior, de tal maneira que seu culturus é tido como apenas como alegórico' ou desprezível. Como descreve Silva (1987, p. 122),

[...] dizia que os negros eram escravos porque lhes veio por maldição deseus avós. Porque estes, cremos ser descendentes de Cã, filho de Noé, que descobriu as vergonhas do pai. Por isso são negros e sofrem outras misérias. Portanto são condenados por Deus a serem sempre escravos dos brancos (SILVA, 1987, p. 122).

Pensamentos como esses disparam o olhar para uma das chaves dos processos de interiorização sofrida por essa população. Segundo esse pensamento, podemos presumir que não pode haver beleza vinda de seres amaldiçoados e condenados pelo Deus judaico-cristão, retratado como um homem branco de olhos claros e aparência europeia. A colonização desconsidera outra cultura, saberes e etnias, em prol de si mesma e de sua soberania. "Eis a virtude dos explicadores: o ser que inferiorizaram, eles o amarram pelo mais sólido dos laços ao país do embrutecimento: a consciência de sua superioridade.” (Rancière, 2002, p. 42). Acerca do pensamento desse autorsobre uma educação autônoma e emancipatória, podemos perceber que os processos formativos e intelectuais vêm se pautando por meio de camadas sociais e de sua importância, de forma que o afro-brasileiro não tenha acesso ao conhecimento das produções da África no Brasil, ou das produções afrodiaspóricas realizadas em solo brasileiro.

A arte, ao longo da história, vem se desenvolvendo por diversas narrativas e, com ela, todo legado social e político do período em que se faz instaurada. Pelo viés político, surge a válvula motriz disparadora para essa produção artística. As artes possibilitam o livre agir, de forma a perceber que o corpo do artista em questão já se tornaria um forte instrumento político de resistência no processo de criação (Gilroy, 2007; 2017). Isto é, trata-se de compreender esse corpo como norteador de um processo criativo para romper com o dogmatismo canônico europeu das artes, já em um rompimento com a mea culpa que nos diz Fanon (2008, p. 29):

De uma vez por todas, a realidade exige uma compreensão total. No plano objetivo como no plano subjetivo, uma solução deve ser encontrada. E é inútil vir com ares de mea culpa, proclamando que o que importa é salvar a alma. (FANON, 2008, p. 29) 
Trazer para o corpo-memória-identidade os processos de matriz africana e especificá-lo com olhos em Mumbuca se torna, além de uma ação de resistência em território estranho, tipicamente branco e elitizado. Falar da dor de pessoas que sofre o silêncio de sua expressão plural e étnica é ser porta voz deste silêncio estruturado e institucionalizado. A consciência da situação afrodiaspórica, combustível para esta criação, fora permeada pela necessidade de potencializar a visibilidade de pessoas, comunidades e práticas esquecidas - embora seja o artista produtor um homem afrodiaspórico de pele preta, ou seja, e diáspora africana e também sofredor das agruras da colonização racista e opressora, logo, com mais tendência a se sensibilizar (pela empatia representativa) tornou-se nítido o sufocamento do quilombo Mumbuca e de sua cultura de forma a criar espanto pelo aspecto de que não existe, ou não se tem o conhecimento de um real e efetivo trabalho para potencializar a fala daquela comunidade. O direito de ir e vir lhes fora tomado, a exploração cultural e de sua(s) identidade(s) em prol de um sistema mercadológico lhes é imposto por vezes como única e exclusiva forma de sobrevivência ${ }^{15}$.

Acredita-se que as populações afrodiaspóricas mesmo que silenciadas, se expressam por meio de seu corpo (Gilroy, 2007; 2017). O 'negro' é tenaz em seu expressar pelo corpo e com o corpo, de uma corporeidade admirável, sua dança, seu gestual é sinônimo de uma identidade marcante e específica. Assim, essa produção não deveria se tornar uma teatralização de uma comunidade, sim uma experiência performativa sobre a mesma. Em se tratando de propor uma ação performativa, vale destacar que:

O performer como alguém distinto do ator-intérprete é essa capacidade de condução do espetáculo-ritual, valorizando a live art, a arte que está acontecendo ao vivo, no instante presente. (COHEN, 2007, p. 109, grifos do autor)

É sobre isso que se trata a performance arte Mumbuca. Sobre essas amarras impostas pelo colonizador que quer impedir o colonizado de existir em sua pluralidade, sobre a falsa ideia de inferioridade de pessoas racializadas $^{16}$, sobre a

\footnotetext{
${ }^{15}$ Sobre o tema de comunidades tradicionais e produção artesanal, há um trabalho interessante com título: Políticas Culturais, Comunidades e Patrimônios no Brasil: algumas questões epistêmicas (Lopes; Totato; Barros, 2014).

${ }^{16}$ Um conceito construído no e justificando o processo de colonização. Raça também é um elemento que não apenas informa, mas organiza e estrutura todas as Ciências Sociais modernas, por isso, os Estudos Culturais, Pós-Coloniais e Decoloniais têm os colocado cada vez mais em rasura, salvo em movimentos
} 
forma sufocante como pessoas e grupos vindouros da África vêm sendo tratado ao longo da história. Mumbuca(performance) fala de uma comunidade quilombola do estado do Tocantins que sofre as dores do esquecimento e do silenciado pelos governos estadual e municipal. Mumbuca é a voz que grita um grito abafado e que diariamente resiste ao esquecimento de seus direitos. Desse modo, um homem tido como 'negro', com roupas brancas, pés descalços, imobilizado pela opressão, sua voz abafada, de pés e mãos atadas, na cabeça, coroa de rei, que um dia foi. Corpo cansado de lutar, exala um gemido de esperança, ao som do atabaque, seu coração pulsa. Pisa nessa terra-chão de "alma negra e corpo negro". Não existe opressor que suporte a força que faz essa terra-chão tremer, sangue de pessoas trazidas da África salpicado com terra vermelha, nesse lato-solo se fez. Feitores da tirania e da falsa soberania, saibam que a voz do quilombo irá ecoar. Afinal,

[...] o corpo humano mediado por tecnologias: o corpo humano atual, desde a mais tenra idade, cotidianamente transpassado por técnicas imperceptíveis ou não; o corpo do outro que da mesma forma se constrói; a imagem de outros corpos (espectros), que também nos tornam conscientes de nossos próprios, imagem impressa, imagem-movimento transmitida, distorcida, corrigida, sincopada..., essa que se torna objeto de desejo, desejo de ser, desejo de tornar-se, mas também desejo de manipulação, de possessão; nossos corpos e suas próteses, sejam elas meios de locomoção, de leitura, de visão, de audição ou de criação, todas elas mais ou menos interativas; enfim corpos constantemente redimensionados por novas tecnologias; logo, novos corpos e novas consciências. (MEDEIROS, 2005, p.150)

Dessa maneira, optou-se, por meio do corpo e da imagem, criar novas experimentações artísticas. Utilizar das narrativas artísticas como forma de expressão pode possibilitar ao artista de forma direta ou subjetiva transpor seu propósito criativo (objeto estético), se o mesmo o tem, para uma possível identificação ou sensibilização de seus espectadores, levando em consideração que, ao se tratar de artes visuais, podemos identificar que existem produções que são desenvolvidas apenas pelo aspecto da beleza, ou até mesmo que viés de que não se faz necessário um discurso para que um objeto seja considerado arte.

Nessa performance arte, o trabalho é desenvolvido por meio de um exercício investigativo e identificativo, na qual a obra se desenvolve de forma interna para o externo, partindo de um auto reconhecimento para externalização do objeto em questão. Foi preciso identificar-se com Mumbuca, seus moradores e práticas de forma a ser palpável sua cultura e expressividade. Assim sendo, ao culminar os estudos em

que a ressemantizam (Bhambra; 2014; Connel; 2012; Grosfoguel; 2016). Por essa razão que o termo negro, quando aparece ao longo do texto, encontra-se entre aspas. 
uma arte performance entendemos que não se tratava apenas de um corpo afrodiasporizado em cena, mais de um artista em uma construção partindo da identificação, da memória e dos sentidos e afetos em consonância com a sua própria individualidade, criando a sensação de pertencimento, optando-se mesmo que por meio da narrativa artístico performativa experienciar este silenciamento sofrido pelo quilombo Mumbuca.

\section{DOS ATRAVESSADOS AO REATRAVESSAMENTOS EM PERFORMANCE ARTÍSTICA: MUMBUCA (R)EXISTE}

Nesse fragmento, há exposição da materialidade do transver Mumbuca, na síntese artística performática (re)atravessada pelos relatos do Diário dos Sentidos e Permissões ${ }^{17}$, produzidos a partir de um corpo-memória que se inscreve no mundo da diáspora africana brasileira experimentando a transposição das dores experienciadas em arte e tensiona, como propõem Fanon (2008, p. 191), na frase última de seu livro Pele Negra, Máscaras Brancas: "Minha última prece; Ô meu corpo, faça sempre de mim um homem que questiona".

Adentrando, assim, a performance Mumbuca, faz-se necessário apontar que a construção de uma produção artístico performativa após a experimentação afetiva, estética transpondo-a para a linguagem artístico poético-performativo embasada em uma historicidade e identidade de umacomunidade, além de uma grande responsabilidade, sem dúvidas cria uma relação processual entre artista-obra e identidade estudada (Cassiano, 2017, s/p).

Após o processo de imersão e pesquisa, a performance se realizou em parceria com outro artista plástico, loiro de olhos claros. Elucidar esse processo de colonização por meio das artes visuais, naquele momento tornou-se um desafio. Não se tratava de representação, como já explanado, muito menos de expor um corpo 'negro' aos flagelos sofridos promovidos por europeus no período da escravatura negra institucionalizada no Brasil. O intuito nessa produção fora atingir o campo sensorial, afetivo e cognitivo, por isso optou-se por elementos subjetivos e não representativos de forma que cada elemento fosse um dissipador, conforme figura 01.

Figura 01 - Performance Mumbuca na Fundação Cultural de Palmas Agosto de 2017

\footnotetext{
${ }^{17}$ As partes que pertencem ao Diário serão sinalizadas para leitoras e leitores com marcação gráfica.
} 

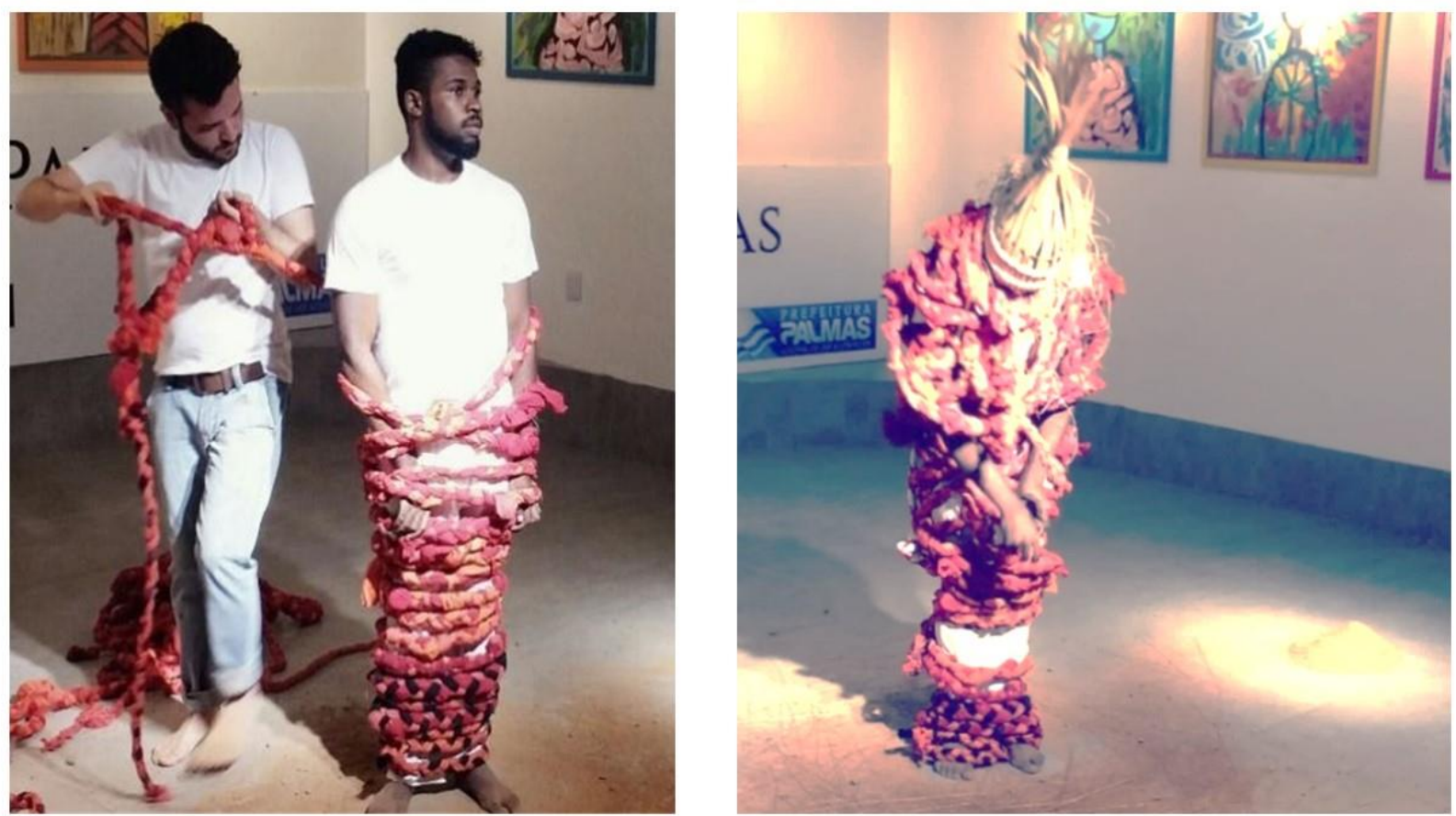

Fonte: Morais (2017) - Acervo pessoal do artista

Legenda: Artista plástico Ronan Gonçalves atuando na performance (imagem à direita) e detalhe da coroa de palha de buriti fabricada pelo artista Thiago Cassiano que fora amarado na imagem à direita.

Sobre o processo criativo, destacam-se algumas tessituras de memórias registradas no Diário dos Sentidos e Permissões:

\begin{abstract}
Durante a pesquisa alguns elementos me atravessaram esteticamente e afetivamente e percebo serem disparadores poéticos para este trabalho. Torna-se imprescindível o elemento terra, pois notou-se a necessidade de aterrar-me como afrodiasporádico no chão singular de Mumbuca. O corpo afrodiasporádico como instrumento de (re) existência e junto dele um legado histórico esquecido, de rei escravizado em outra terrachão-motriz-início. Não que estes elementos signifiquem da mesma forma para os espectadores desta obra performativa, sua correlação identitária e afeita surge da imersão artista-Mumbuca-corpo afrodiasporádico para corpo afrodiasporádico e como ela reverbera como resultado artístico e poético. (CASSIANO, 2017, s/p).
\end{abstract}

Dentre os elementos, iniciemos o desenredar pelo elemento terra, o qual vem como força motriz de uma cultura. Crê-se que na terra, o humano estabelece sua identificação de mundo; a travessia do Atlântico não apenas retira o africano de sua terra-mãe, mais força-o a perder contato com sua identidade.

Já a coroa de buriti, uma palha de uso corriqueiro da comunidade Mumbuca, parte do culturus dessa comunidade. A coroa de buriti surge como elemento semântico e histórico nesta obra, trata-se dos reis e rainhas da África que foram retirados de sua terra 
para serem escravizados. Vale ressaltar que muitos morreram lutando pela liberdade dos seus.

A cordas de nós é a colonização sofria pelo 'negro', a morte de um identitário de uma cultura. Soltar-se dessas amarras é justamente a coexistência de uma cultura que luta para sobreviver em consonância com corpo africano escravizado que renega ser servil.

Cada nó que perpassa este corpo "negro", são lembrança de outrora onde o choro contido na garganta não podia se esvair na travessia de volta para casa, agora não mais nos porões do esquecimento. Cada nó vem como um percalço das agruras sofridas por este corpo afrodiaporádico marginalizado, rechaçado. Com estes mesmos nós, fez-se a força necessária para resistência a soberania ditatorial. Transpor dor em força, estar, para então ser (...) (CASSIANO, 2017, s/p).

O corpo afrodiasporizado: Como explanado brevemente, o 'corpo negro', com olhar firme e cabeça erguida emerge como potente e pleno em sua cultura e existência. Trata-se de um corpo afrodiasporizado que não se submete aos mandos do opressor (branco). Isso para elucidar o corpo que mantém sua cultura e identidade viva das mais diversas maneiras possíveis. Esse corpo presente, trajando vestimentas brancas, ligação com sua religiosidade, devoção aos Vuduns e aos ancestrais.

Destaca-se também a ligação cosmogônica com a terra-chão África, com o pulsar dos atabaques que reverbera pelo 'corpo negro' como forma latente de uma corporeidade e expressividade. Esse elemento surge como motriz disparadora deste libertar-se do corpo colonizado, sendo ele o coração pulsante da África que chama para volta às origens.

Corpo Branco: Europeu, colonizador e opressor de todas culturas que não a da Europa imperialista, especificamente aqui opressora das culturas dos povos da África (em diáspora ou não). Surge também como representação de um estado efetivado por importâncias e do reconhecimento do 'negro' como corpo à margem da sociedade. Evidente que cada espectador irá reconhecer ou não, ou criar relação ou não com cada elemento utilizado mediante a forma com que a obra reverbera em seu estado emocional, afetivo e estético, sendo essa a tríade por onde estruturou-se a criação desta performance arte. Sendo assim, sobre o ato performático, Cohen (2002, p. 28) acrescenta-se que:

Apesar de sua característica anárquica e de, na sua própria razão de ser, procurar escapar de rótulos e definições, a performance é antes de tudo uma expressão cênica: um quadro sendo exibido para uma plateia não caracteriza uma performance; alguém 
pintando esse quadro, ao vivo, já poderia caracterizá-la (COHEN, 2002, p. 28; grifos do autor).

Como uma árvore que finca suas raízes, as populações da diáspora africana percorrem sua nova narrativa sob a chave das rotas transatlânticas estéticas, epistêmicas e políticas (Costa, 2006; Gilroy, 2007;). Com elementos cênicos permeados por uma estética contemporânea, essa produção não se trata do belo na obra, mas da beleza que existe por trás da obra. Com um público massivamente caucasiano e de homens, o sujeito que se liberta (Thiago Cassiano) das amarras em experiência performativa, mesmo que simbolicamente, era dizer que Mumbuca existe e tem voz. Com duração de aproximadamente 40 minutos, olhares observaram atentos a esta 'de(s)colonização' por meio arte performativa. Ao fim do processo criativo, 'negro', suado, ofegante, assim me recordo dos irmãos em África que, após horas a fio de trabalho, ainda possuíam força suficiente para cantar, dançar e não deixar o que latente em seu corpo morrer, sua cultura, sua origem. Pessoas, comunidades, coletivos e organizações afrodiaspóricos resistem, Mumbuca resiste, o artista da diáspora africana brasileira resiste.

\section{CONSIDERAÇÕES FINAIS}

Eu vim de lá, eu vim de lá pequenininho

Mas eu vim de lá pequenininho Alguém me avisou

Pra pisar nesse chão devagarinho Alguém me avisou

Pra pisar nesse chão devagarinho! (Yvonne Lara da Costa, 1997)

Bem como nos aponta a ancestralidade africana, representada aqui na poética da mestra do samba Ivone Lara, e pisando devagarinho nessa terra embranquecida, estamos e somos (re) existência. Buscamos apresentar um resultado das pesquisas realizadas acerca da comunidade Mumbuca do estado do Tocantins, que resultou em uma produção artístico performativa, cuja pretensão percussiva foi atravessar a história da comunidade, relacionando-a às problemáticas raciais, políticas e ideológicas sofridas pela comunidade quilombola em questão, mas também comunidade afro-brasileira como um todo.

As artes são potentes ferramentas para manutenção e transformação de identitários, reinventando rotas de entrada e saída da África (rizomas). É no fazer criativo que a humanidade exerce de forma inconsciente o desfazer dos nós, como na 
produção performática relatada. O desamarrar-se na ação performativa é justamente isso, é refletir sobre o processo colonizador que somos diariamente submetidos a viver. E esse processo ocorre de forma ardilosa ao ponto de levar o próprio 'negro' a acreditar em sua falta de potência para existir de forma plural e igualitária frente a sociedade.

Não foi de se estranhar a existência de um único 'negro' no primeiro compartilhamento público desta produção artística. Um 'negro' sendo amarrado por um homem caucasiano não causou espanto ao público ali presente, o que lhes chamou a atenção foi ao som do atabaque, este 'negro' se desvencilhar da amarra do opressor. Podemos observar que casa grande e senzala não são apenas resquícios de um triste e doloroso passado, mas permanecem transvestidos de sobrados e favelas na realidade deste país.

Falar de Mumbuca, falar do quilombo é falar um pouco que está envolto em pessoas, comunidades práticas da diáspora africana e suas identidades. Ao escolher uma narrativa artística como forma norteadora da voz silenciada é acessar locais onde o quilombo não tem acesso, de forma que cause inquietude nos espectadores e apreciadores de arte para uma realidade eminente e evidente.

Dessa maneira, este trabalho surge para elucidar o silenciamento que a comunidade Mumbuca vem sofrendo ao longo de sua existência, seja ele institucional ou não. Deve-se compreender que aquele lugar possui pessoas, culturas, não um local de exploração cultural e promoção de uma falsa diversidade que, por sua vez não é respeitada por órgãos públicos e não públicos do Tocantins. Tanto Mumbuca quanto outros quilombos do Brasil necessitam ter voz, as pessoas da diáspora africana ainda sofrem os resquícios deixado pela escravidão. Mesmo após a Lei n 3.353, de 13 de Maio de 1888 que 'deu fim' à escravatura oficial no Brasil, se faz preciso refletir sobre qual liberdade estamos falando, e para quem está lei realmente foi assinada, afinal sempre que necessário reivindicam "Medos Brancos" perante as "Ondas Negras". Viver em um país onde caucasianos se assustam em ver um 'negro' se desvencilhar de amarras é prova que ainda existe muito para ser feito. Mumbuca, quilombo do interior do Tocantins, vem tendo sua tecnologia patrimonial e identitária em prol do processo colonizador a ele instaurado. Isto posto, com a produção artística do Diário dos Sentidos e Permissões, a performance Mumbuca e agora esse artigo, busca-se ser uma vibração audível para vozes silenciadas, um minuto de barulho por uma vida de silêncios. Não obstante, finalizamos esse trabalho com um pensamento retirado do Diário dos Sentidos 
e Permissões, caderno utilizado para anotações técnicas, referências e de sensações obtidas durante o processo criativo do experimento performativo produzida por um dos autores: "É preciso ser ponte quando não existem braços fortes para atravessar o rio. É preciso ser ponte para si e para o outro, mesmo em dias de chuvas torrenciais, é preciso ser, para poder estar." (Cassiano, 2017, s/p).

Por fim, dedica-se esta produção científica, bem como a performance arte Mumbuca à comunidade do quilombo Mumbuca do Tocantins. Por sua (re)existência em ser, por toda ancestralidade africana e por poder, pelas narrativas artísticas, expressar a voz silenciada, eterna gratidão e respeito, por toda inspira(ção) poética e por todo atravessamento afetivo.

\section{REFERÊNCIAS}

ANJOS, A. C. C. dos. Do girassol ao capim dourado: apropriação e ressignificação de elementos naturais na narrativa identitária do Estado do Tocantins. Porto Alegre, RS: Editora Fi, 2017.

; SOUSA, K. C. Estratégias de Conservar o Poder: a construção midiática do termo apropriação cultural e o caso do uso turbante. In: Revista da Associação Brasileira de Pesquisadores/as Negros/as (ABPN), [S.1.], v. 9, n. 23, p. 249-266, nov. 2017.

BHAMBRA, G. As possibilidades quanto à sociologia global: uma perspectiva pós-colonial. In: Revista Soci edade e Estado,v. 29, n. 1, jan./abr., 2014. Disponível em: http://www.scielo.br/scielo.php?script=sci arttext\&pid=S010269922014000100008\&lng=en\&n rm=iso. Acesso em 20 maio 2019.

BERGER, P. L.; LUCKMANN, T. A construção social da realidade: tratado da sociologia do conhecimento. Tradução de Floriano Souza Fernandes. 24 Ed. Petrópolis (RJ), 2004.

BRASIL, [Constituição (1988)]. Constituição da República Federativa do Brasil. Brasília, DF: Presidencia da República, [2016]. Disponível em:http://www.planalto.gov.br/ccivil 03/constituicao/constituicao.htm. Acesso em 01 jun. 2019.

CASSIANO, T. F. Diário dos Sentidos e Permissões. s/e: Palmas, 2017.

COSTA, I. L. da. Alguém me avisou. Columbia/Sony Music, 1997, Rio de Janeiro. 1 Intérpretes Ivone Lara da Costa (Ivone Lara) com participação especial de Gilberto Gil.

COSTA, K. Alunos da comunidade Mumbuca voltam a estudar após incêndio em ponte - Jornal do Tocantins. Jornal do Tocantins, Palmas, 16 dez. 2016. Caderno Estado. Disponível em : https://www.jornaldotocantins.com.br/editorias/estado/alunos-da-comunidade-mumbucavoltam-a-estudar-ap\%C3\%B3s-inc\%C3\%AAndio-em-ponte-1.1167664. Acesso em 15 maio 2019.

COSTA, S. Dois Atlânticos: teoria social, anti-racismo, cosmopolitismo. Belo Horizonte: UFMG, 2006. 
CAVAGLIER, M.C.S.; MESSEDER, J. C. Plantas Medicinais no Ensino de Química e Biologia: Propostas Interdisciplinares na Educação de Jovens e Adultos. In: Revista Brasileira de Pesquisa em Educação em Ciências, v. 14, n.1, 2014.

COHEN, R. Performance como linguagem. 2. ed. - São Paulo: Perspectiva, 2007. (Debates; 219. Dirigida por J. Guisburg).

CONNELL, R. O Império e a Criação de Uma Ciência Social. In: Contemporânea - Revista de Sociologia da UFSCar v.2 n.2 Disponível em: http://www.contemporanea.ufscar.br/index.php/contemporanea/article/view/85/50. Acesso em: 19 maio 2019.

DOLCE; MEDEIROS. A resistência das comunidades quilombolas no Jalapão. RevistaVaidapé, São Paulo, ano 4. A Rua Grita. Cidade. Disponível em: http://vaidape.com.br/2014/04/a-resistencia-das-comunidades-quilombolas-no-jalapao/. Acesso em 01 fev.2019.

DUBOIS, W. E. B. As almas da gente negra. Trad., introd. e notas Heloísa Toller Gomes. Rio de Janeiro: Lacerda Ed., 1999.

FANON, F. Pele negra, máscaras brancas. Trad. de Renato da Silveira. Salvador : EDUFBA, 2008.

G1 TOCANTINS. Justiça ordena reconstrução de ponte incendiada em povoado do Jalapão. G1 Tocantins, Palmas, 24 jan. 2017. Disponível em: http://g1.globo.com/to/tocantins/noticia/2017/01/justica-ordena-reconstrucao-de-ponteincendiada-em-povoado-do-jalapao.html. Acesso em 15 maio 2019.

GILROY, P. Entre Campos: nações, culturas e o Fascínio da Raça. Trad. Célia Maria Marinho de Azevedo; et al. São Paulo: Annablume, 2007.

O Atlântico Negro: modernidade e dupla consciência. Trad. Cid Knipel Moreira. 2. Ed. 1. Reimpr. São Paulo: Editora 34; Rio de Janeiro; Universidade Candido Mendes, Centro de Estudos Afro-Asiáticos, 2017.

GROSFOGUEL, R. A estrutura do conhecimento nas universidades ocidentalizadas: racismo/sexismo epistêmico e os quatro genocídios/epistemicídios do longo século XVI. In: Revista Estado e Sociedade, v. 31, n.1: pp. 25-49. Disponível em: http://www.scielo.br/pdf/se/v31n1/0102-6992-se-31-01-00025.pdf. Acesso em 15 maio 2019.

KICKANTE. Construção da Ponte na Mumbuca. Disponível em https://www.kickante.com.br/campanhas/construcao-da-ponte-na-mumbuca. Acesso 08jun. 2019

LOPES, J.R.; TOTARO, P.; BARROS, E. P. Políticas Culturais, Comunidades e Patrimônios no Brasil: algumas questões epistêmicas. In: Seminário Internacional - Políticas Culturais, 5,2014, Rio de Janeiro, Anais, Rio de Janeiro: Fundação Casa de Rui Barbosa, 2014, p. 1-15. Disponível em: http://culturadigital.br/politicaculturalcasaderuibarbosa/files/2014/06/Jos\%C3\%A9Rog\%C3\%A9rio-Lopes-et-alii.pdf. Acesso em 01 jun.2019.

MEDEIROS, M. B. de. Aisthesis: estética, comunicação e comunidades. Chapecó: Argos, 2005.

MOURA, C. Sociologia política da guerra camponesa de Canudos. São Paulo: Expressão Popular, 2000. 
PINO, A. O Biólogo e o cultural nos processos cognitivos, em linguagem, cultura e cognição: reflexão para o ensino de ciências. Campinas: Gráfica da Faculdade e Educação, 1997.

RANCIÈRE, J. O mestre ignorante. Cinco lições sobre a emancipação intelectual. Trad. Lílian do Valle. Belo Horizonte: Autêntica, 2002. (Série: Educação. Experiência e sentido).

RATTS, A. Eu sou atlântica: sobre a trajetória da vida de Beatriz Nascimento. São Paulo: Imprensa Oficial do Estado de São Paulo: Instituto Kuanza, 2007.

RUTHERFORD, J. O terceiro espaço. Uma entrevista com Hommi Bhabha. In: ARANTES, A. A. A. (Org.) Revista do Patrimônio Histórico e Artístico Nacional, n. 24, p. 36-41, Campinas: Serifa Produção Gráfica LTDA, 1996.

SCHWARCZ, L. M.; VAREJÃO, A. Pérola Imperfeita: A História e as Histórias na Obra de Adriana Varejão. Rio de Janeiro: Cobogó, 2014.

SILVA, D. de M. Identidade afro-brasileira: abordagem do ensino da arte. In: Comunicação\& Educação, São Paulo, n. 10, p. 44-49, 1997. Disponível em: http://www.revistas.usp.br/comueduc/article/view/36321. Acesso em 01 jun.2019.

Recebido em 30/04/2019

Aprovado em: 30/06/2019 